GUIDE TO ANALYSIS 
Consultant Editor: David A. Towers, Senior Lecturer in Mathematics, University of Lancaster

Titles Available

Abstract Algebra Linear Algebra

Analysis

Further titles are in preparation. 


\title{
Guide to Analysis
}

\author{
F. Mary Hart
}

Department of Pure Mathematics

University of Sheffield

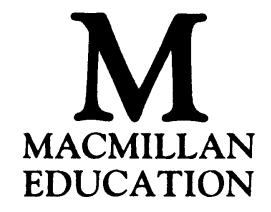


All rights reserved. No reproduction, copy or transmission of this publication may be made without written permission.

No paragraph of this publication may be reproduced, copied or transmitted save with written permission or in accordance with the provisions of the Copyright Act 1956 (as amended), or under the terms of any licence permitting limited copying issued by the Copyright Licensing Agency, 7 Ridgmount Street, London WC1E 7AE.

Any person who does any unauthorised act in relation to this publication may be liable to criminal prosecution and civil claims for damages.

First published 1988

Published by

MACMILLAN EDUCATION LTD

Houndmills, Basingstoke, Hampshire RG21 2XS

and London

Companies and representatives

throughout the world

British Library Cataloguing in Publication Data

Hart, F. Mary

Guide to analysis.--(Macmillan

mathematical guides).

1. Calculus

I. Title

$515 \quad$ QA303

ISBN 978-0-333-43788-9 ISBN 978-1-349-09390-8 (eBook)

DOI 10.1007/978-1-349-09390-8 


\section{CONTENTS}

Editor's foreword

vii

Preface

viii

Glossary of symbols and notation

1 NUMBERS AND NUMBER SYSTEMS

1.1 Natural numbers

1.2 Integers

1.3 Rational numbers

1.4 The real number system

Appendix: Mathematical induction

2 SEQUENCES $\quad 25$

$\begin{array}{ll}2.1 \text { Introduction } & 25\end{array}$

$\begin{array}{ll}2.2 \text { Sequences } & 26\end{array}$

2.3 Standard limits $\quad 42$

2.4 Some general results for sequences $\quad 47$

2.5 Subsequences $\quad 51$

Appendix: Triangle inequalities $\quad 56$

$\begin{array}{ll}\text { Table of standard limits } & 58\end{array}$

3 INFINITE SERIES

$\begin{array}{lll}3.1 & \text { Introduction } & 62\end{array}$

$\begin{array}{lll}3.2 & \text { Series and notation } & 64\end{array}$

$\begin{array}{lll}3.3 & \text { Tests for convergence } & 69\end{array}$

3.4 Absolute convergence, rearrangement of series,

$\begin{array}{ll}\text { Appendix } & 100\end{array}$

$\begin{array}{ll}\text { Tests for convergence — summary } & 103\end{array}$ 
4 FUNCTIONS Limits of functions, continuous functions 106

4.1 Limits of functions 106

4.2 Continuity 139

4.3 Some properties of continuous functions on closed intervals

5 DIFFERENTIABLE FUNCTIONS Differentiable functions, Rolle's theorem, mean value theorem, Taylor's theorem, l'Hôpital's rule, maxima and minima, Taylor series 160

5.1 Differentiation $\quad 160$

5.2 Rolle's theorem and the mean value theorem 173

5.3 Taylor's theorem $\quad 180$

5.4 L'Hôpital's rule $\quad 183$

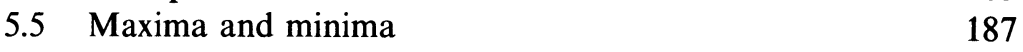

$\begin{array}{ll}\text { Index } & 201\end{array}$ 


\section{EDITOR'S FOREWORD}

Wide concern has been expressed in tertiary education about the difficulties experienced by students during their first year of an undergraduate course containing a substantial component of mathematics. These difficulties have a number of underlying causes, including the change of emphasis from an algorithmic approach at school to a more rigorous and abstract approach in undergraduate studies, the greater expectation of independent study, and the increased pace at which material is presented. The books in this series are intended to be sensitive to these problems.

Each book is a carefully selected, short, introductory text on a key area of the first-year syllabus; the areas are complementary and largely selfcontained. Throughout, the pace of development is gentle, sympathetic and carefully motivated. Clear and detailed explanations are provided, and important concepts and results are stressed.

As mathematics is a practical subject which is best learned by doing it, rather than watching or reading about someone else doing it, a particular effort has been made to include a plentiful supply of worked examples, together with appropriate exercises, ranging in difficulty from the straightforward to the challenging.

When one goes fellwalking, the most breathtaking views require some expenditure of effort in order to gain access to them: nevertheless, the peak is more likely to be reached if a gentle and interesting route is chosen. The mathematical peaks attainable in these books are every bit as exhilarating, the paths are as gentle as we could find, and the interest and expectation are maintained throughout to prevent the spirits from flagging on the journey. 


\section{PREFACE}

The transition from sixth form to university or polytechnic can be traumatic. Students have to adapt to different styles of teaching with lectures replacing lessons and at the same time they are often presented with material which is unlike anything they have encountered before. The provision of suitable textbooks can go some way to alleviating the problem. As far as pure mathematics is concerned, analysis, which is central to most undergraduate courses in mathematics, is likely to provide the biggest stumbling-block. The subject itself is intrinsically difficult. The final polished version we have today owes its form to years of concentrated work by many celebrated mathematicians, and students often find it very daunting to be faced with this finished product. They seldom realise just how much effort went into its making, who did the work or why they did it. This account therefore includes some historical notes and anecdotes which help to put the subject into context and, it is hoped, enliven the text for the reader.

This volume is written specifically for students meeting analysis for the first time. It is designed so that it can be used as a textbook in conjunction with a lecture course in analysis or it can be used by students wishing to teach themselves the subject - independent of any lecture course. For this reason numerous worked examples are included with very detailed solutions to enable the reader to check that the concepts and definitions are understood. When working the exercises the reader is given the opportunity to receive a little help (or inspiration!) without being given the answer, as the answers and the hints for solutions are recorded in separate sections. In practice, one exercise successfully completed by the reader (even with the help of a few hints) can teach more than several examples read from the text.

Analysis traditionally contains numerous theorems and proofs. These theorems are the tools of the trade and we cannot just dispense with large numbers of them in order either to cut down the size of the volume or to make the learning process appear easier. Neither can we simply omit their proofs. Before using a result we must know for certain that it is true. The need for proof is something which has always been recognised to a greater or lesser extent. Historical records show that the ancient Greek mathematicians living 
centuries before Christ acknowledged this, and, indeed, some of our presentday proofs, like the contradiction argument, stem from their work. However, the use of the link between limits of functions and sequences allows us a few economies and reduces the number of separate proofs necessary.

For many undergraduates the greatest hurdle is the problem posed by the idea of rigour. They are unsure about how much detail needs to be included and how much may reasonably be omitted. The reader of more advanced texts can be assumed to have sufficient judgement to be able to cope when details are not carefully spelled out. A more elementary text, however, needs different treatment and it seems prudent to include all the small details. This may make the definitions and theorems appear a little more cumbersome, but it leaves the reader in no doubt as to what is being assumed. The benefits far outweigh any superficial disadvantage occurring from the longer, more detailed statements. Since repetitions can be valuable for reinforcing knowledge, some statements and proofs which closely resemble earlier ones are nevertheless recorded in detail rather than being dismissed with an assertion of the form 'the proof is similar to that of...'.

Finally, I would like to record my profound thanks for all the secretarial help I have received during the preparation of this volume. My thanks go to Anne Hall and Janet Williams and particularly to Alex Cain who has undertaken the bulk of the work. 


\section{GLOSSARY OF SYMBOLS AND NOTATION}

$\mathbb{N} \quad$ Set of all natural numbers. This set consists of the numbers $0,1,2,3, \ldots$

$\mathbb{Z} \quad$ Set of all integers

$\mathbb{Z}^{+} \quad$ Set of all positive integers

$\mathbb{Q} \quad$ Set of all rational numbers

$\mathbb{R} \quad$ Set of all real numbers

$\mathbb{R} \backslash\{0\} \quad$ Set of all non-zero real numbers

$|x| \quad$ Modulus of a real number $x$. Its value is $x$ if $x \geqslant 0$ and its value is $-x$ if $x<0$. Thus $|x|=+\sqrt{x^{2}}$

$>\quad$ Greater than

$<\quad$ Less than

$\ngtr \quad$ Not greater than

$\Varangle \quad$ Not less than

$\geqslant \quad$ Greater than or equal to

$\leqslant \quad$ Less than or equal to

$\{x: \mathrm{P}(x)\} \quad$ The set of all $x$ such that $\mathrm{P}(x)$ holds

$\{a, b, c, \ldots\}$ The set consisting of $a, b, c, \ldots$

$\rightarrow \quad$ Tends to

$\rightarrow \quad$ Does not tend to

$\epsilon \quad$ Belongs to

$\notin \quad$ Does not belong to

$\left(a_{n}\right)_{n=1}^{\infty} \quad$ Infinite sequence $a_{1}, a_{2}, a_{3}, \ldots$ whose $n$th term is $a_{n}$. (This notation is used when we wish to make clear which values are assumed by the subscript $n$ )

$\left(a_{n}\right) \quad$ Infinite sequence with terms of the form $a_{n}$. (This notation is used when it is clear from the context which values are assumed by $n$ )

$\left(a_{n_{k}}\right)_{k=1}^{\infty} \quad$ Subsequence $a_{n_{1}}, a_{n_{2}}, a_{n_{3}}, \ldots$ of the sequence $\left(a_{n}\right)$

$\sum \quad$ Sum of 
$\sum_{n=1}^{\infty} a_{n}$

This is used in two senses. It is used formally to stand for the infinite series $a_{1}+a_{2}+a_{3}+\ldots$ It is also used for the sum of the infinite series in the case in which the series is convergent. The context makes clear which meaning is appropriate

$\sum_{k=1}^{n} a_{k} \quad$ The sum of the $n$ terms $a_{1}+a_{2}+\ldots+a_{n}$

$\gamma \quad$ Euler's constant

$f: A \rightarrow \mathbb{R} \quad$ Function $f$ from $A$ into $\mathbb{R}$ i.e. $f$ has domain of definition $A$ and range a subset of $\mathbb{R}$

$\log x \quad$ The natural logarithm of $x$. Throughout this volume all logarithms are to the base $\mathrm{e}$

$(a, \infty) \quad$ Set of all real numbers $x$ such that $x>a$

$[a, \infty) \quad$ Set of all real numbers $x$ such that $x \geqslant a$

$(-\infty, b) \quad$ Set of all real numbers $x$ such that $x<b$

$(-\infty, b] \quad$ Set of all real numbers $x$ such that $x \leqslant b$

$(a, b) \quad$ The open interval $(a, b)$. It consists of all the real numbers $x$ such that $a<x<b$

$[a, b] \quad$ The closed interval $[a, b]$. It consists of all the real numbers $x$ such that $a \leqslant x \leqslant b$

$x \rightarrow a \quad x$ approaches $a$ (two-sided limit)

$x \rightarrow a^{+} \quad x$ approaches $a$ through values greater than $a$ (one-sided limit)

$x \rightarrow a^{-} \quad x$ approaches $a$ through values less than $a$ (one-sided limit)

$g \circ f \quad g$ composition $f$. This is the function such that $(g \circ f)(x)=g(f(x))$

$f^{-1} \quad$ Inverse function of $f$

$f^{\prime} \quad$ Derivative of $f$

IVT Intermediate value theorem

MVT Mean value theorem 